\title{
Brief
}

\section{Lessons from the first patient to undergo full aortic root replacement using a homograft: A 29-year follow-up}

\author{
Sajiram Sarvananthan, MBBS, Giovanni Melina, MD, PhD, and Magdi H. Yacoub, FRS, London, United Kingdom
}

From the Academic Department of Cardiothoracic Surgery, National Heart and Lung Institute, Imperial College, London, United Kingdom.

Received for publication Oct 23, 2004; accepted for publication Nov 4, 2004.

Address for reprints: Professor Sir Magdi Yacoub, The Magdi Yacoub Institute, Harefield Research Foundation, Harefield, Middlesex UB9 6JH, United Kingdom (Email: m.yacoub@imperial.ac.uk).

J Thorac Cardiovasc Surg 2005;129:1430-1

$0022-5223 / \$ 30.00$

Copyright $\odot 2005$ by The American Association for Thoracic Surgery

doi:10.1016/j.jtcvs.2004.11.009

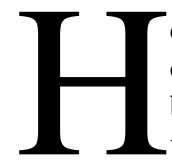

omograft aortic valve replacement (AVR) has been shown to have many advantages over other forms of AVR. ${ }^{1,2}$ The technique of full aortic root replacement, introduced by us in $1975,{ }^{3}$ has the potential to reproduce, at least in part, the normal native aortic valve behavior. ${ }^{4}$ There is, however, a debate about the early and long-term results of this operation, particularly in relation to overall valve performance, aortic root dilatation and calcification, left ventricular function, fate of coronary anastomoses, sensitization against allograft, and any other complications.

Although we report about a single patient, this study represents the longest follow-up for this operation, which is of historical value and could provide some valuable insights.

\section{Clinical Summary}

In 1975, a 28-year-old woman presented with worsening dyspnea and increasing shortness of breath with intermittent chest pain. She was found to have severe aortic regurgitation with an aneurysm of the ascending aorta, confirmed by an aortogram. Her father had died suddenly of medionecrosis of the aorta.

Operative technique and findings. She underwent an antibiotic-sterilized homograft root replacement with reimplantation of the coronary arteries. At operation, the native aortic valve was bicuspid, and the ascending aorta was aneurysmal. The aortic homograft was sutured in position; the coronary arteries were dissected and reimplanted into the homograft, with a 30-mm Dacron tube graft used to extend the homograft and replace the ascending aorta.

The postoperative period was uneventful, and she made a quick recovery and was discharged on the 14th postoperative day.

Quality of life. "I ask you, if I still have to wait long for my operation? I feel so unsettled and unable to sort my future. I am a young person with a small child to consider, and all I want is to be able to go out, get a job, and be independent once more. In present position I cannot do anything!" This was the main concern of the patient before her operation. After the operation, she gained strength, was symptom-free, and became more active. She went on to have another healthy baby.

Follow-up. The patient remained completely asymptomatic until 1992 when she presented again with increasing shortness of breath on exercise, episodes of chest tightness, and occasional palpitations.

She was found to have severe aortic regurgitation caused by active infective endocarditis; her blood pressure was $120 / 50 \mathrm{~mm} \mathrm{Hg}$, with no other significant abnormalities. She was started on antibiotics, but her condition deteriorated rapidly, requiring an emergency operation consisting of replacement of the infected aortic root with an antibiotic-sterilized homograft, which was used for re-replacement of the root with implantation of the coronary arteries. She made an uncomplicated postoperative recovery and was given 4 weeks of intravenous antibiotic therapy.

During the last 12 years, after the second operation, she has been followed up regularly. She is now asymptomatic and is leading a normal life. Her blood pressure is managed with medication. Recent cardiovascular magnetic resonance imaging (Figure 1, A, and Figure 2) showed the left ventricle to be contracting well (ejection fraction, 69\%), without dilatation (end-diastolic volume, $127 \mathrm{~mL}$; endsystolic volume, $39 \mathrm{~mL}$ ) and no hypertrophy (mass index, $47 \mathrm{~g} / \mathrm{m}^{2}$ ); the peak velocity across the aortic valve was $2.1 \mathrm{~m} / \mathrm{s}$, without detectable regurgitation; the annulus measured $22 \mathrm{~mm}$, sinuses of Valsalva, 

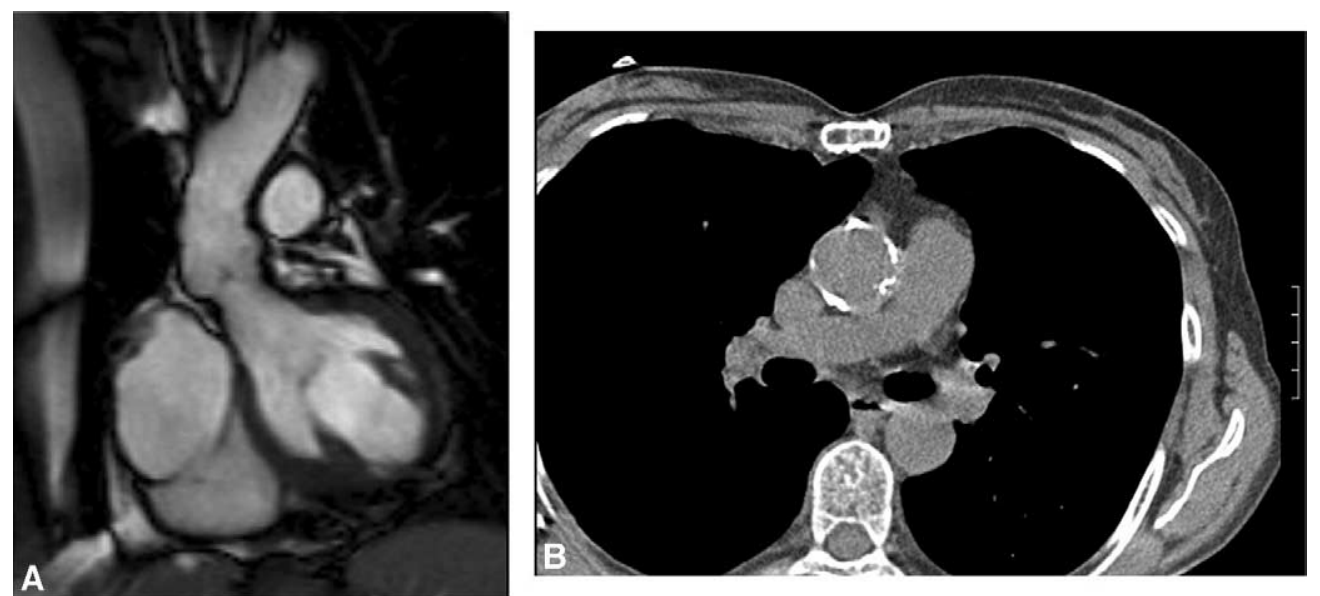

Figure 1. A, Magnetic resonance imaging of left ventricular outflow tract with neo-aortic root. B, Electron beam tomography of the neo-aortic root and valve cusps. Calcium score: neo-aortic root wall, 9034; calcified volume score: neo-aortic root wall, $7187 \mathrm{~mm}^{3}$. The leaflets and the coronary buttons are free of calcium.
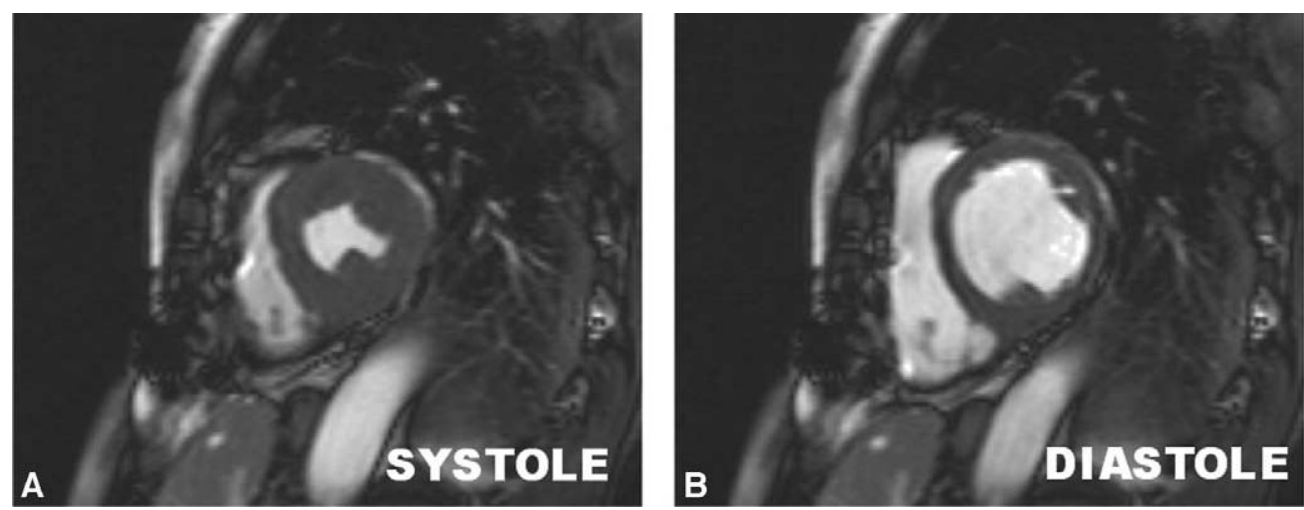

Figure 2. Magnetic resonance imaging of the heart showing a preserved function and dimensions of both ventricles.

$26 \mathrm{~mm}$, and sinotubular junction, $24 \mathrm{~mm}$. She also underwent an electron beam tomography scan of the aortic root (Figure 1,B).

\section{Comment}

This single-case report illustrates several important points.

The antibiotic-sterilized homograft can function well for 16 years, and a second root continues to function 12 years after the second operation, providing an excellent quality of life, including the capability to have a second baby, and does not degenerate faster than the first one. A homograft root is not free of risk of endocarditis.

The homograft root does not dilate and become aneurysmal. Calcification is common but does not involve the coronary buttons and the aortic leaflets, which continue to function well over a prolonged period of time. In addition, the homograft root, with a Dacron extension for replacement of an aneurysm of the ascending aorta, has provided long-term good result, without development of further aneurysm of the arch.

A second operation after root replacement is feasible and safe; this point has been borne out by our large experience. ${ }^{5}$ Finally, the homograft root appears to preserve left ventricular function over a period of 29 years, without progressive deterioration.
It is hoped that this information provides insight for both clinicians and researchers.

\section{References}

1. Yacoub M, Rasmi NR, Sundt TM, Lund O, Boyland E, Radley-Smith R, et al. Fourteen-year experience with homovital homografts for aortic valve replacement. J Thorac Cardiovasc Surg. 1995;110:186-94.

2. Lund O, Chadrasekeran V, Grocott-Mason R, Elwidaa H, Mazhar R, Khaghani A, et al. Primary aortic valve replacement with allografts over twenty-five years: valve-related and procedure-related determinants of outcome. J Thorac Cardiovasc Surg. 1999;117:77-91.

3. Gula G, Ahmed M, Thompson R, Radley-Smith R, Yacoub M. Combined homograft replacement of the aortic valve and aortic root with reimplantation of the coronary arteries [abstract]. Circulation. 1976; 54(suppl):II-150.

4. Yacoub MH, Kilner PJ, Birks EJ, Misfeld M. The aortic outflow and root: a tale of dynamism and crosstalk. Ann Thorac Surg.1999; 68(3 suppl):S37-43.

5. Melina G, Al-Obaidi M, Yacoub MH. Early and long-term outcome of rereplacement of the aortic valve following homograft full root replacement. A 28-year experience [abstract]. Circulation. 2003;108(suppl):IV-620. 